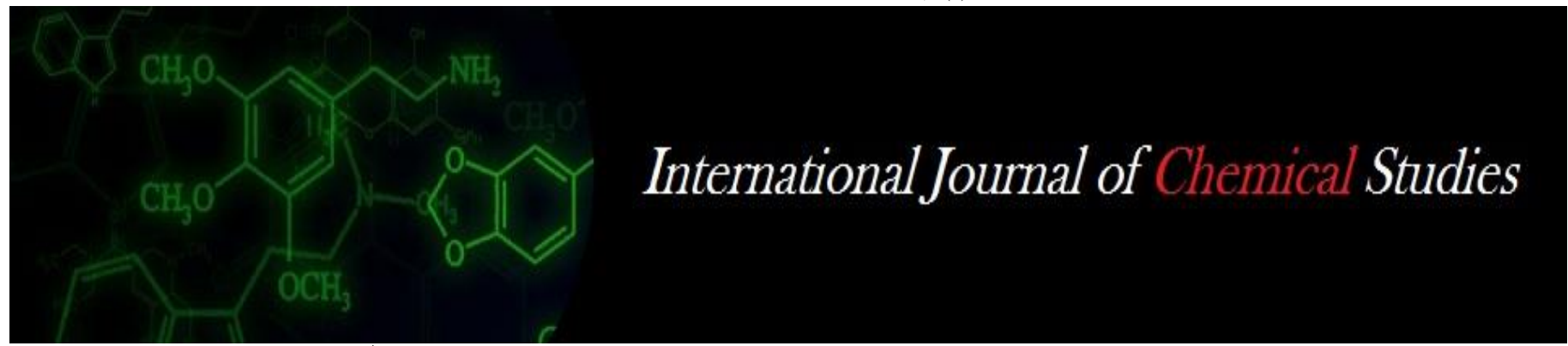

P-ISSN: 2349-8528

E-ISSN: 2321-4902

www.chemijournal.com

IJCS 2020; 8(6): 407-410

(C) 2020 IJCS

Received: 09-09-2020

Accepted: 13-10-2020

Dr. M Raju

Tamil Nadu Rice Research

Institute, Aduthurai, Thanjavur,

Tamil Nadu, India

Dr. K Subrahmaniyan

Tamil Nadu Rice Research

Institute, Aduthurai, Thanjavur,

Tamil Nadu, India

Dr. S Porpaavai

Soil and Water Management

Research Institute, Thanjavur,

Tamil Nadu, India

Dr. M Babu

Tamil Nadu Rice Research

Institute, Aduthurai, Thanjavur,

Tamil Nadu, Indias

Dr. C Sharmila Rahale

Tamil Nadu Rice Research

Institute, Aduthurai, Thanjavur,

Tamil Nadu, India
Corresponding Author:

Dr. M Raju

Tamil Nadu Rice Research

Institute, Aduthurai, Thanjavur,

Tamil Nadu, India

\section{Diversification of suitable alternate cropping system for enhancing productivity, profitability and resource use efficiency in Cauvery delta zone of Tamil Nadu}

\author{
Dr. M Raju, Dr. K Subrahmaniyan, Dr. S Porpaavai, Dr. M Babu and Dr. \\ C Sharmila Rahale
}

DOI: https://doi.org/10.22271/chemi.2020.v8.i6f.10804

\begin{abstract}
The field experiment was carried out in two location namely at Tamil Nadu Rice Research Institute, Aduthurai, Thanjavur and Soil and Water Management Research Institute, Thanjavur during 2016 - 2019 under irrigated conditions with an objective of alternate cropping system to get more remuneration. The treatments imposed such as pulse - rice - pulse, maize - rice - pulse and rice - rice - pulse cropping systems in both Aduthurai and Thanjavur. The results revealed that higher rice grain equivalent yield, System productivity, Land use efficiency, Production efficiency and Relative economic efficiency were higher in pulse - rice - pulse and maize - rice - pulse system in Aduthurai and Thanjavur centres respectively. Similarly, the less water requirement was observed in the same systems. Based on the results obtained it is recommended that higher profit could be achieved in pulse - rice - pulse and Maize -rice -pulse systems in Aduthurai and Thanjavur respectively with consuming lesser water requirement.
\end{abstract}

Keywords: Rice equivalent yield, System productivity, Land use efficiency, Production efficiency, Relative economic efficiency

\section{Introduction}

Rice (Oryza sativa L.) occupies a pivotal place in Indian agriculture. It is the staple food for about 70 per cent of population and a source of livelihood for about 120-150 million rural households. It accounts for about 43 per cent of total food grain production and 55 per cent of cereal production in the country. Rice is a primary energy source or high calorie food and it contains less protein than wheat. The protein content of milled rice is usually 6-7 per cent. The by-products of rice milling are used for various purposes. Rice bran is used as cattle and poultry feed. Rice hulls can be used in manufacturing of insulation materials, cement and card board and as a litter in poultry keeping. Besides, rice straw is also used to feed cattle (Singh et al. 2005). In India, rice is cultivated over an area of 43.95 million hectares with a production of 106.54 million tonnes. In Tamil Nadu, rice is grown in an area of 2.04 million hectare with total production of 9.98 million tonnes. In Cauvery Delta Zone (CDZ), major crop is rice which is grown in an area of 14.47 lakh ha which contributes 11 per cent of the total area of Tamil Nadu. The CDZ includes Thanjavur, Nagapattinam, Tiruvarur, Trichy and parts of Karur, Ariyalur, Pudukkottai and Cuddalore districts of Tamil Nadu.

The practice of double cropping of rice in kuruvai (June - September) and Thaladi (October February) is on the increase because of the development of short and medium duration high yielding rice varieties (Subrahmaniyan et al., 2016) ${ }^{[9]}$. But the double cropped lands have been subjected to lot of hardship in the past years due to uncertainty in the monsoon as well as release pattern of canal water. The delay in release of canal water leads to delayed planting of kuruvai crop in the month of July which subsequently results in delayed planting of second crop (Thaladi). Problems and prospects of rice production in different ecosystems vary greatly. Now-a-days, agriculture in general and rice farming in particular are facing threats of water and labour scarcity in the delta in alarming rate, besides energy usage for land preparation (Umamageshwari et al. 2020) ${ }^{[11]}$. 
Similarly, mono cropping of rice or rice-rice cropping system has led to several environmental hazards viz., soil salinity and alkalinity problems, besides methane emission from the rice field also led to environmental problems. To overcome these deleterious effects an alternate cropping system or crop diversification is need of the hour. Crop diversification and intensification of rice-based or alternate cropping system for rice-rice system to enhance the productivity per unit resource is very pertinent. Crop diversification shows lot of promises in alleviating problems viz., water scarcity, excess use of nitrogenous fertilizer, soil deterioration etc., besides, fulfilling basic needs for cereals, pulses, oilseeds, vegetables and also regulating farm income, withstanding weather aberrations, controlling price fluctuation, ensuring balanced food supply, conserving natural resources, reducing the chemical fertilizer and pesticide loads, ensuring environmental safety and creating employment opportunity. In this context, efforts are being made to promote diversification of rice based cropping sequence or development of an alternate cropping systems to rice-rice in our country as well as Cauvery delta zone of the Tamil Nadu with cereals and pulses for sustaining the productivity and doubling the farm income. Therefore, keeping all these points in view, the present investigation was carried out to studies the economic feasibility of alternate sequential cropping systems to rice-rice (Oryza sativa L.) in both old and new delta of Cauvery sub basin of Tamil Nadu.

\section{Material and methods}

The field experiment was carried out in two location namely at Tamil Nadu Rice Research Institute, Aduthurai, Thanjavur and Soil and Water Management Research Institute, Thanjavur during 2016 - 2019 under irrigated conditions. The experimental site of Aduthurai was located at $11^{\circ}$ North latitude and $79^{\circ}$ East longitude at an altitude of $19.5 \mathrm{~m}$ above Mean Sea Level (MSL). The region is characterized by a subtropical climate with a hot dry summer (March-June), and extended wet period from September to February. Average annual rainfall is about $1078 \mathrm{~mm}$, majority of which was received during North East Monsoon. The soil of the TRRI, Aduthurai was clay in texture and moderately drained. The experimental soil was classified as alluvial clay and composed of $13.6 \%$ sand, $61.2 \%$ silt, and $25.3 \%$ clay, pH $7.5(1: 5 \mathrm{H} 2 \mathrm{O})$ and EC $11.6 \mathrm{mS} \mathrm{m}^{-1}$ with low in available nitrogen $(130 \mathrm{~kg}$ $\left.\mathrm{ha}^{-1}\right)$, high in available phosphorus $\left(65 \mathrm{~kg} \mathrm{ha}^{-1}\right)$ and medium in available potassium $\left(400 \mathrm{~kg} \mathrm{ha}^{-1}\right)$.

The geographical location of the SWMRI, Thanjavur has the reference to $79^{\circ}$ east longitude, $10^{\circ} 45$ North latitude and $50 \mathrm{~m}$ above mean sea level. The average annual rainfall is $930 \mathrm{~mm}$. The mean maximum and minimum monthly temperature vary from $39.9^{\circ} \mathrm{C}$ in May to $29.4^{\circ} \mathrm{C}$ in December and from $27.1^{\circ} \mathrm{C}$ in May to $20.8^{\circ} \mathrm{C}$ in January respectively. The soil was sandy clay loam, neutral in reaction ( $\mathrm{pH}$ 6.5), low in available nitrogen $(217 \mathrm{~kg} / \mathrm{ha})$, high in available phosphorus (265 $\mathrm{kg} / \mathrm{ha}$ ) and medium in available potassium (153 kg/ha) with organic carbon content $0.390 \%$. The treatment imposed in the trials is furnished hereunder

Table 1: Treatments details

\begin{tabular}{|c|c|c|}
\hline June - July & September-October & January - Febraury \\
\hline Pulse & Rice & Pulse (Blackgram) \\
\hline Maize (CoMH 6) & Rice & Pulse (Blackgram) \\
\hline Rice & Rice & Pulse (Blackgram) \\
\hline
\end{tabular}

All agronomical packages of practices were followed to raise the crops in different cropping system. The yield obtained in each crop is recorded every year. Economic yields of component crops were converted into rice-equivalent yield (REY), taking into account the prevailing market prices of different crops in the cropping sequences. The above values were computed as per the following formula given by Verma and Midgal (1983) ${ }^{[12]}$.

$(\mathrm{YCC} \times \mathrm{MPCC})+$ Yield of main crop $\left(\mathrm{kg} \mathrm{ha}^{-1}\right)$ $\operatorname{REY}\left(\mathrm{kg} \mathrm{ha}^{-1}\right)=\frac{\left(\mathrm{C} C \times \mathrm{Mrice} \text { of main crop }\left(₹ \mathrm{ha}^{-1}\right)\right.}{\text { Pro }}$

Whereas, YCC $=$ Yield of component crop $\left(\mathrm{kg} \mathrm{ha}^{-1}\right)$ and MPCC=Market price of component crop $\left(₹ \mathrm{ha}^{-1}\right)$. System productivity values in terms of $\mathrm{kg}$ REY ha ${ }^{-1} \mathrm{day}^{-1}$ were worked out for the total production by means of rice equivalent yield in a crop rotation divided by year duration. Production efficiency was expressed as the ratio of system productivity in $\mathrm{kg} \mathrm{REY} / \mathrm{ha}$ to total duration of the system in days. Total field duration of a cropping system expressed in percentage of 365 days was taken as the land use efficiency, LUE Tomar and Tiwari (1990) ${ }^{[10]}$. Land-use efficiency was obtained by taking total duration of crops in an individual crop rotation divided by 365 days. Apparent nutrient productivity was calculated by dividing the equivalent yield of the system by the total quantity of nutrient used. Cost of cultivation, gross returns and returns were calculated in terms of ₹ ha ${ }^{-1}$, benefit cost ratio was calculated by dividing gross returns by cost of cultivation. Relative economic efficiency (REE) is comparative measure of economic gains over the existing system. The following method was used to calculate the REE and expressed as percentage.

$$
\operatorname{REE}(\%)=\frac{\mathrm{A}-\mathrm{B}}{\mathrm{B}} \times 100
$$

Whereas, $\mathrm{A}=$ Net returns of diversified system $\left(₹ \mathrm{ha}^{-1}\right), \mathrm{B}=$ Net returns of existing system ( $₹ \mathrm{ha}^{-1}$ ). Crop profitability ( $₹$ $\mathrm{ha}^{-1}$ day $\left.^{-1}\right)$ is calculated by dividing net returns with duration of the crop, whereas system profitability ( $₹$ ha $^{-1}$ day $^{-1}$ ) is calculated by dividing net returns with duration of the year.

\section{Results and discussion \\ Rice equivalent yield and System Productivity}

At Aduthurai, among the three cropping system, higher Rice Grain Equivalent Yield (system productivity) was observed with Pulse - Rice - Pulse (11602 $\mathrm{kg} \mathrm{ha}^{-1}$ year $^{-1}$ ) followed by Maize - Rice - Pulse (11269 kg ha-1 year $^{-1}$ ) and. Rice - Rice Pulse $\left(11024 \mathrm{~kg} \mathrm{ha}^{-1}\right.$ year $\left.^{-1}\right)$. The yield varied from 2.2 to 5.24 per cent over existing rice-rice - pulse cropping system. These results are in conformity with finding of [11] who reported that inclusion of legume during summer/rabi in rice based cropping system resulted in an increased in productivity and profitability. At Thanjavur, among the three cropping system, higher Rice Grain Equivalent Yield (system productivity) was observed with Maize - Rice - Pulse (12502 $\mathrm{kg} \mathrm{ha}^{-1}$ year $\left.^{-1}\right)$ followed by Rice - Rice - Pulse (11779 $\mathrm{kg} \mathrm{ha}^{-1}$ year $^{-1}$ ) and Pulse - Rice - Pulse (10014 kg ha-1 year $\left.^{-1}\right)$.

The higher rice equivalent yield indicate that the residual advantage of a legume crop and maize contribution in total system productivity in Aduthurai and Thanjavur respectively. This might be due to higher production potential of pulse along with the good market price of pulse and rice that yielded better grain yield than rest other cropping systems. The pulses in rice -rice and pulse cropping system also markedly contributed to the system productivity, besides 
enhancing the productivity of succeeding crops and consequently resulted in higher crop equivalent yield and system productivity which was almost equal to the conventional rice-rice cropping system. Similar findings are also reported by shrikant et al., $2014^{[6]}$.

\section{Land use efficiency}

Irrespective of the centres, among different cropping systems rice-rice - pulse and maize - rice -pulse cropping system accounted for highest land use efficiency (88\%) and it was followed by pulse - rice -pulse (74 \%) cropping system (Table.3). It was mainly attributed to rice and maize crops in respective sequences because these crops occupied the field for about 115 and 130 days, respectively than other treatments led to achieve higher land use efficiency. The lowest land use efficiency $(74 \%)$ was recorded in pulse - rice - pulse cropping system indicated that it has the scope to include one more short duration crop like blackgram for soil fertility restoration.

\section{Production efficiency}

At Aduthurai, significantly superior production efficiency was recorded with pulse - rice (42.97 $\mathrm{kg} \mathrm{REY} \mathrm{ha}^{-1} \mathrm{day}^{-1}$ ) compared to other cropping systems. The next best performed cropping systems were maize - rice -pulse (35.22 kg REY ha-1 day $\left.^{-1}\right)$. With respect to Thanjavur, significantly superior production efficiency was recorded with maize - rice $(39.07 \mathrm{~kg}$ REY ha ${ }^{1}$ day $^{-1}$ ) compared to other cropping systems. The next best performed cropping systems were pulse - rice -pulse (37.09 $\mathrm{kg}$ REY ha ${ }^{-1}$ day $^{-1}$ ). It was attributed to higher crop equivalent yield which in turn led to harness the higher production efficiency of the system. Similar findings have also been reported by Kapil Saroch et al., $2005^{[4]}$. Mishra et al. (2007) [5] also reported that higher productivity and profitability through inclusion of vegetables and pulses in rice based cropping system.

\section{Apparent nutrient use productivity}

Pulse-rice-pulse cropping system registered significantly higher apparent nutrient productivity $(187.7 \mathrm{~kg}$ REY kg-1 nutrient applied) over other cropping systems. The next best cropping system was found to be rice - rice - pulse cropping system (124 kg REY kg-1 nutrient applied) in Aduthurai. Similarly, rice - rice - pulses cropping system registered higher apparent nutrient use productivity $\left(257.4 \mathrm{~kg} \mathrm{REY} \mathrm{kg}^{-1}\right.$ nutrient applied) in Thanjvur, as compared to other systems. The next best cropping system was found to be rice - rice pulse cropping system (195.7 $\mathrm{kg} \mathrm{REY} \mathrm{kg}^{-1}$ nutrient applied). These results are also in line with findings of Alok Kumar et al., 2012. In the present investigation, this higher apparent nutrient productivity might be due to high crop equivalent yield per unit of nutrient applied. The apparent nutrient use productivity of pulse - rice - pulse was higher in both Aduthurai and Thanjvaur Centre than the existing rice-rice cropping system (Table 3 ).

\section{Effect of water requirement and water use efficiency by different cropping systems}

With respect to water requirement in Aduthurai, Pulse - Rice Pulse system consumed lesser water requirement of $1483 \mathrm{~mm}$ with water saving of 12.76 and 56.43 per cent over Maize Rice - Pulse (1700 mm) and Rice - Rice - Pulse (2320 mm) respectively. Similar trend was also observed in water use efficiency. At Thanjavur, Pulse - Rice - Pulse system consumed lesser water requirement of $1533 \mathrm{~mm}$ with water saving of 12.40 and 52.40 per cent over Maize - Rice - Pulse $(1750 \mathrm{~mm})$ and Rice - Rice - Pulse $(2337 \mathrm{~mm})$ respectively where as higher water use efficiency of $7.15 \mathrm{~kg} \mathrm{ha}^{-1} \mathrm{~mm}^{-1}$ recorded in Maize - Rice - Pulse as compared to Pulse - Rice - Pulse (6.52 $\left.\mathrm{kg} \mathrm{ha}^{-1} \mathrm{~mm}^{-1}\right)$ and Rice - Rice - Pulse (5.05 kg $\left.\mathrm{ha}^{-1} \mathrm{~mm}^{-1}\right)$.

\section{Pre and post soil nutrient status influenced by cropping} system

Available soil nutrients revealed that Pulse - Rice - Pulse system has recorded higher nutrient status as compared to Maize- Rice-Pulse and Rice-Rice-Pulse in both Aduthurai and Thanjavur centres which was followed by rice - rice - pulse crop.

\section{Effect of cropping systems on economics}

Economics is the ultimate criteria for acceptance and wider adoption of any technology and, cropping system technology is also no exception to this. Among different indicators of economic efficiency in any production system, a net return has greater impact on the practical utility and acceptance of the technology by the farmers. In the present study eeconomics of the different cropping systems showed that the higher cost of cultivation was noticed in rice-rice cropping system ( $₹ 87000$ and $89500 \mathrm{ha}^{-1}$ ) compared to rest of the cropping systems viz., maize - rice- pulse cropping system (₹ 73167 and $\left.81987 \mathrm{ha}^{-1}\right)$. The inclusion of pulse and maize in the place of rice during kuruvai (June - September) under rice based cropping systems increased the total variable cost due to usage of more fertilizer and human labour engagement. These results are in line with finding of Devkant Prasad et al. 2013. Irrespective of the location, the gross returns were higher in rice - rice - pulses ( $₹ 170049 \mathrm{ha}^{-1}$ ) because of higher value of produce and it was followed by maize-rice -pulse (₹ $183412 \mathrm{ha}^{-1}$ ) cropping system (Table 3). Further highest net profit ( $₹ 92366$ ha $^{-1}$ ) was noticed with pulses - rice - pulses cropping system and this was mainly attributed to higher gross returns and minimum cost of cultivation in Aduthurai whereas in Thanjavur highest net profit ( $₹ 101425 \mathrm{ha}^{-1}$ ) was recorded in maize - rice - pulses system as compared to other system. These results are in conformity with the findings of Honnali and Chittapur (2014) ${ }^{[3]}$. With regards to benefit cost ratio, it was highest in case of pulse - rice - pulse (2.34) mainly due to higher price of pulse and less cost of production. The other best performed cropping systems are maize - rice - pulse (2.26) and lowest in existing system ricerice- pulse (1.96) cropping systems at Aduthurai. In Thanjavur, the higher benefit cost ratio recorded in Maize Rice - pulse system (2.29) as compared to other system like pulse - rice - pulse (1.98) and rice - rice - pulse (1.96). This was mainly due to less cost of production, more yield and higher prices of pulse and maize crops.

\section{Economic profitability and efficiency}

Crop profitability and system profitability varied significantly among different cropping systems. In Aduthurai, higher crop profitability observed with pulse - rice - pulse system (₹ 342.10 ha $^{-1}$ day $^{-1}$ ) compared to rest of the cropping systems (Table. 4). Significantly lower crop profitability was recorded with rice - rice - pulse (₹ $259.53 \mathrm{ha}^{-1}$ day $^{-1}$ ) whereas at Thanjavur, higher crop profitability in maize-rice - pulse cropping system ( $₹ 316.95 \mathrm{ha}^{-1} \mathrm{day}^{-1}$ ) which is followed by pulse - rice - pulse ( $₹ 266.74 \mathrm{ha}^{-1} \mathrm{day}^{-1}$ ). Significantly lower crop profitability was obtained with existing cropping system of rice - rice - pulse (₹ 260.14 ha $^{-1}$ day $^{-1}$ ). 
Similarly, Significantly higher system profitability was obtained with pulse - rice - pulse (₹ 253.06 ha $^{-1}$ day $^{-1}$ ) compared to rest of the cropping systems in Aduthurai. In case of Thanjavur, the higher system profitability of 277.88 $\mathrm{ha}^{-1}$ day $^{-1}$ recorded in Maize - rice - pulse system than other systems viz., existing system rice -rice -pulse $\left(228.07 \mathrm{ha}^{-1}\right.$ day $^{-1}$ ) and pulse - rice - pulse (197.32 ha $^{-1}$ day $\left.^{-1}\right)$. Similar results were also reported by Singh, and Kumar (2014). Profitability depends on the duration of crop and net returns of the system.

\section{Conclusions}

Based on findings of this experiment it can be concluded that pulse - rice - pulse and maize - rice - pulse cropping systems proved to better in terms of production which inturn more profitable and remunerative as they fetched more net returns per unit area for time invested, and can be a better cropping systems in place of rice-rice - pulse for the farmers of Aduthurai and Thanjvaur respectively for higher profitability.

\section{References}

1. Alok Kumar, Tripathi HP, Yadav RA. Intensification and diversification in rice (Oryza sativa) wheat (Triticum aestivum) cropping system for sustainability. Indian $\mathbf{J}$ Agron 2012;57(4):319-322.

2. Devkant Prasad, Yadava MS, Singh CS. Diversification of rice (Oryza sativa) based cropping systems for higher productivity, profitability and resource-use efficiency under irrigated ecosystem of Jharkhand,. Indian J Agron 2013;58(3):264-270.

3. Honnali SN, Chittapur BM. Efficient cropping systems and their energetics for sustainable irrigated tropical ecosystems, Indian J Agron 2014;59(4):556-560.

4. Kapil Saroch, Manoj B, Sharma JJ. Diversification of existing rice (Oryza sativa) based cropping system for sustainable productivity under irrigated conditions, Indian J Agron 2005;50(2):86-88.

5. Mishra MM, Nanda SS, Mohanty M, Pradhan KC, Mishra SS. Crop diversification under rice based cropping system in western Orissa. In: Extended summaries 3 rd National Symposium on Integrated Farming Systems 2007.

6. Shrikant K, Phajage, Upadhyay VB. Effect of rice (Oryza sativa L.) based cropping systems on soil properties and crop productivity. Bioinfolet 2014;11(3a):811-813.

7. Singh DK, Kumar P. Influence of diversification of rice (Oryza sativa) - wheat (Triticum aestivum) system on productivity, energetics and profitability under on-farm conditions. Indian J Agron 2014;59(2):200-203.

8. Singh G, Mehta RK, Kumar T, Singh RG, Singh OP, Kumar V. Economics of rice (Oryza sativa) based cropping system in semi-deep water and flood prone situation in Eastern Uttar Pradesh. Indian J Agron 2004;49(1):10-14.

9. Subrahmaniyan K, Parasuraman VRP, Senthil Kumar G, SharmilaRahale C. Impact of conservation tillage on soil properties and rice yield of rice- rice cropping system. Paper presented at the 4th International Agronomy Congress, New Delhi, India 2016.

10. Tomar SS, Tiwari AS. Production potential and economics of different cropping sequences. Indian $\mathbf{J}$ Agron 1990;35(1, 2):30-35.

11. Umamageshwari C, Raju M, Subrahmanian K. Influence of different establishment methods of rice on the parameters of water, weed, growth and yield under rice rice - Blackgram system 2020.

12. Verma SP, Mudgal SC. Production potential and economics of fertiliser application as resource constraints in maize-wheat crop sequences, Himachal J Agril Res 1983;9(2):89-92. 